\title{
The Opioid Epidemic - Addressing Provider Roles and Responsibilities
}

Anita Modi, MD, Debbie Chen, MD, Neha Bansal Etherington, MD, Brianna Shinn, MD, and Colin Thomas, MD

\author{
PANELISTS \\ Abigail Kay, MD \\ Assistant Dean of Academic Affairs and Undergraduate Medical \\ Education, and Assistant Professor in the Department of \\ Psychiatry and Human Behavior
}

Brooke Worster, MD

Assistant Professor of Palliative Care in the Department of

Family and Community Medicine

Rachel Nash, MD

Chief Resident in the Department of Internal Medicine

Jill Zavodnick, MD

Hospitalist at Thomas Jefferson University Hospital

Ms. Kate Siddiqi

Social worker at Thomas Jefferson University Hospital

Ms. Meghan Morley

Lead Patient Navigator at the Center of Excellence at the Narcotic Addiction Rehabilitation Program (NARP) in the

Division of Substance Abuse

\section{INTRODUCTION}

Colin: This year marks the 19th volume of Jefferson's annual publication spearheaded by Internal Medicine residents and supported by its fellows. Our Editorial Board includes Neha, Debbie, Anita, Brianna, and myself. Our mission is to further medical knowledge by sharing each other's observations and studies both through our publication, which you can find online, as well as through annual discussion at Grand Rounds.

This year, we've chosen to focus on our roles as providers in the midst of the National Opioid Epidemic. The National Institute on Drug Abuse has reported that the number of opioid-related overdose deaths from both illegal and prescription opioids has risen in our state over the last 15 years. This information is available for each state online. While addiction has been a nationwide issue for centuries, provider practices and societal attitudes in relation to opioids has greatly varied. We'll introduce you to our panelists, giving a very brief overview of the history of opioid use in our country, then turning the discussion over to them.
Today, we have Dr. Abigail Kay, Assistant Dean of Academic Affairs and Undergraduate Medical Education and Assistant Professor in the Department of Psychiatry and Human Behavior. Ms. Meghan Morley is the Lead Patient Navigator at the Center of Excellence at the Narcotic Addiction Rehabilitation Program (NARP) in the Division of Substance Abuse. Dr. Rachel Nash is a current Chief Resident in the Department of Internal Medicine. Ms. Kate Siddiqi is a social worker at Jefferson. Dr. Brooke Worster is an Assistant Professor of Palliative Care in the Department of Family and Community Medicine. Dr. Jill Zavodnick is a hospitalist at Jefferson. Drs. Kay, Nash, and Zavodnick and Ms. Morley are members of Jefferson's Opioid Task Force, established in the fall of 2017 to provide structure, focus, and direction to Jefferson's response to the current Opioid Crisis. No one involved with these Grand Rounds has any relevant disclosures.

Brianna: First we're going to go over some definitions so we can all be on the same page as we move forward in our discussion. "Opiate" is a term used to describe any drug derived from actual opium. "Opioid" was a term initially used to describe synthetic or semi-synthetic versions of opiates but has now come to encompass any agent which binds to opioid receptors in the CNS and Gl tract, including natural, synthetic, and semi-synthetic drugs. The body produces natural, endogenous opioids such as endorphins which are unable to independently cause respiratory depression or adequate pain relief in extreme circumstances. Opium alkaloids include morphine and codeine; semi-synthetic opioids resemble the structure of opiates and include heroin, oxycodone, and buprenorphine; and fully synthetic opioids which don't resemble the structure of opiates at all include methadone.

Prescription and illegal opioids can lead to patterns of tolerance, dependence, and addiction with chronic use. We'll go over those three terms as well. Tolerance suggests that a person require higher and/or more frequent doses of drug to achieve desired effects such as pain control. Dependence implies that one's neurons only function normally in the presence of drug and thus that its absence results in withdrawal symptoms. Addiction refers to compulsive or uncontrollable drug-seeking behavior despite harmful consequences-either at work, in relationships, with one's health, or with the law. 
Colin: The Smithsonian published an article just last week called "How Advertising Shaped the First Opioid Epidemic, and What It Can Teach Us About the Second." It sets the stage in the 1800s, when physicians and manufacturers who recognized the effectiveness of morphine as a painkiller began incorporating it into many drugs. There was no Food and Drug Administration (FDA) to regulate safe and standardized production yet, so medicines were sold without a full listing of their active ingredients and often without need for a doctor's prescription. Cocaine and alcohol were also common additives to popular medications then.

Morphine was heralded as a cure-all, recommended by physicians at the time for everything from wounds obtained by soldiers during the Civil War to the menstrual cramps and teething pains of their wives and children. Use of IV and oral formulations of opioids was ubiquitous and most patients who sought prescriptions were of respectable social backgrounds. Once doctors and journalists began to take note of the addictive nature of these medications, the Pure Food and Drug Act was created in 1906 and eventually gave rise to the FDA.

Brianna: Now I'm going to walk us through a timeline of opioid development, which stretches back to the 1800 s all the way to today. This timeline is interesting because it clearly demonstrates the swinging pendulum in regards to the support and criticism surrounding the use of opioids. We'll start way back in the 1800 s when morphine was first isolated from plant. Merck began marketing it in the 1820s in a pill form. Codeine was first isolated in the 1830 s and used for cough. Then the syringe was invented in 1850 s and you can see morphine really came into use in its IV form during the Civil War in the 1860s. Then, in the 1870s, heroin was invented and marketed as a safer drug. You'll see this theme as we go forward-the realization that a certain opioid or type of opioid was addictive, government intervention, then the production and marketing of a "safer drug." Next, as awareness of opioid addiction grew in the 1900s, the act giving rise to the FDA was established. This reduced the use of morphine both as prescribed and over-the-counter medications, but doctors were instead encouraged to employ "less addictive" painkillers such as oxycodone and methadone in subsequent years.

In the 1970s, pharmaceutical companies which had previously limited their marketing to physicians also began redirecting their advertising to consumers directly which contributed to a nationwide clamor for these semi-synthetic and thus reportedly safer agents. When the addictive nature of these agents were subsequently elucidated, the War on Drugs was declared and the "Just Say No" campaign launched. Just a decade later, the Drug Enforcement Agency was also established at this time. Extended-release versions of morphine, oxycodone, and fentanyl were later released for chronic non-cancer pain and again purported to be less addictive. Educational programs funded by pharmaceutical companies and supported by such institutions as the American Pain Society (APS) designated pain as "the fifth vital sign" as recently as the 2000 s and prescription opioid use peaked in 2010 with 82 prescriptions for every 100 persons. This takes us to present day; with the rise of opioid-related ED visits for nonfatal overdoses as well as actual deaths, the pendulum has swung back in the direction of discouraging opioid use and the establishment of the Prescription Drug Monitoring Program (PDMP).

\section{TRANSCRIPT}

Colin: In the last couple years, President Trump has declared the Opioid Crisis a national epidemic and public health emergency, vowing to dedicate \$13 billion to new resources for addiction treatment, physician education on appropriate prescribing, and prosecution of drug traffickers. Most recently, the CDC has released an annual surveillance report of drug-related risks and outcomes for 2017, reflecting on the previous year. We'll leave up these statistics as we begin our conversation with our panelists, centered on our role as providers in the midst of the Opioid Crisis. To begin, I think it would be nice to just go down the line and explain your role and experience taking care of patients in the Opioid Crisis.

Dr. Kay: I'm Dr. Abby Kay and from 2005-2015, I was the Medical Director of NARP. When I became the Dean, I switched to being a regular, everyday doctor there and I teach both locally and nationally about how to use medically-assisted treatment options and how to treat addiction in general.

Dr. Worster: Hi, I'm Dr. Brooke Worster and I live in the palliative care world so I sort of straddle this interesting bifurcation of opioids in that we employ them often in end-of-life care. I also live in the world of cancer pain management and, I'm happy to report, cancer survivorship which entails a lot of substance abuse disorders which are often iatrogenically created. I'm a part of the Task Force here and deal with a lot of substance abuse disorders, opioid abuse disorders, but have to maintain some availability because they aren't all bad.

Dr. Nash: I'm Rachel Nash, I live in the resident world and am one of our current chiefs. I became interested in this topic mainly out of frustration, being on Green medicine and being a night Medical Admitting Resident and feeling like I was taking care of the same patients over and over again that struggled with opioid use disorder. As a result of that, I did additional training in addiction medicine in Boston and have been involved in the Task Force ever since, focusing on resident education and increasing the use of the PDMP and familiarity with suboxone on campus here. 
Dr. Zavodnick: I'm Jill Zavodnick, I'm one of the hospitalists here which makes me a very frequent inpatient prescriber and occasional short-term outpatient prescriber of opioids. I've seen lots of the medical complications of addiction as well as the medical consequences of our inability to treat pain very well, so that's part of what got me interested in this issue-the consequences of hospitalized addicted patients with withdrawal symptoms that we're not great at managing which makes us not great at managing their other medical problems. My goal is to help inpatient providers figure out what to do with people who are suffering from withdrawal when they are in the hospital partially to facilitate their medical care and then figure out how we can use our inpatient visits as a way to help get people more engaged and linked into recovery.

Ms. Morley: Hi everyone, I'm Meghan Morley, the Lead Patient Navigator at the Center of Excellence for the Department of Psychiatry in the Division of Substance Abuse. I'm a professional counselor and started at NARP as a therapist doing substance abuse counseling there for methadone maintenance patients. The Center of Excellence is a grant that was given to the university from Governor Tom Wolf to help connect people with treatment through warm handoffs, and most of my efforts are focused at Methodist Hospital but also at Main Campus. I also work with offices that prescribe suboxone to help people connect with counseling services, so I'm happy to be here today to talk about our service and how we can provide you with support in connecting your patients with treatment.

Ms. Siddiqi: I'm Kate Siddiqi and I'm an inpatient social worker and have been here for 14 years as of today itself. We have a large number of patients as you've all mentioned who have cycled back through, and it's very frustrating but we've had success from Meghan and the Center of Excellence connecting people to the outside. There are barriers that we're slowly trying to whittle away at, but they are institutional and outside of our system, so it's a group process to work through those together.

Colin: Thank you. What Brianna and I will do is ask a few questions before punting it to the audience to ask some questions too. Our first question is, How has increased awareness of the opioid epidemic changed your practice of prescribing opioids and counseling patients on their appropriate use.

Dr. Nash: In the inpatient world, the pendulum has swung from using opioids to really try other alternatives before going to opioids for pain management. Most providers are more aware of the risks and benefits of using opioids. What's astounding is that the more I read about chronic opioid use, the more confused l've become. I do worry about the limits that are being proposed on the number of morphine equivalents providers can prescribe, leaving a patient population that are like pain refugees in a way. I think we really need to evaluate prescribing patterns of physicians as a whole at our institution, which we're beginning to do, and identify variations in practice habits. This is much like the tenets of quality and safety-where you evaluate your performance, see where your outliers are, and address them. Our Opioid Task Force looked at surgical data, habits of surgeons who were prescribing narcotics after routine procedures such as cholecystectomy. We called patients a few days after discharge and found that $60 \%$ of these patients' narcotics were not being used. That's a real area of us to evaluate our prescribing habits, what patients really need, and reduce the number of opioids in the system that may theoretically decrease diversion. That's certainly a way that some patients become addicted. So I would say that the pendulum is swinging and prescribers are aware of risks, but still work needs to be done in evaluating variations in prescribing patterns.

Dr. Worster: Personally, I have changed my prescribing practices significantly; I live in the outpatient world. I probably prescribe opioids nearly every single day. I take care of patients with cancer, I take care of patients who are dying. But I think there's a couple of things that have really meaningfully contributed to the conversation that I'm having a lot more with patients. One of them is the PDMP and I'm so frustrated that Pennsylvania was one of the last adopters of this nationwide-and for a while we couldn't actually query New Jersey or Delaware, so you had a partial picture but not even the whole picture. Finally, that's in place and I think that is something that is just best practice; everyone that we give a medication to, we should be looking. The other thing is that public awareness. I think public understanding of the crisis has people coming into my office saying, "I'm scared of opioids." I just left a patient today who is 70 years old and has metastatic prostate cancer who basically became non-ambulatory because he had such bad bony pain but didn't want to take opioids because he was scared of becoming addicted. So as the pendulum swung so far one way, with pain being the fifth vital sign and us saying "Everyone needs opioids," I also do caution that we can't throw the baby out with the bathwater here. There is some goodness to this, and I think the best change that could be happening out of all of this in terms of prescribing patterns is that it really becomes an informed conversation between the patient and the provider. We have to understand what is driving patients who are either taking the medication or not, how to take it safely, and how to get rid of it if they're not taking it. Eighty percent of the opioids people take are outside of one physician prescribing them, so we're missing the boat in connecting the dots between "What pill am I going to write for you today?" and what happens beyond that setting. 
Dr. Nash: I think two things the audience should be aware of is that there is now a Take-Back box in Jefferon's apothecary, open the same hours as that pharmacy, where you can bring back your medications. You can tell your patients that the box is available now. I also just got off the phone with Dr. Jeff Riggio who wanted me to inform you that the PDMP is going to be integrated into Epic very soon. You'll be able to press Care Everywhere and see the PDMP data if you are registered. This is another reason Dr. Zavodnick and I are really pressing house staff to become registered with PDMP because of its value.

Dr. Kay: One comment I want to make-and, yes, there are exceptions, but in general-for every patient that I've admitted to the Methadone Clinic who has said, "I had no addiction until I got the Percocet for this surgery," that hasn't been the case. The problem is, there are things that are addictions that we don't consider addictions; when they were 12 they were smoking a pack a day of cigarettes or using alcohol heavily or using marijuana on a regular basis. We sort of throw those out the window. My feeling is that these are really important things to pick up on and think about, I think the history is the piece we're often missing. I'm not saying that if a patient has that history, it puts them at risk for future addiction. It's not that you wouldn't give them opioids if necessary, but you might have a different conversation with them. The thing that drives me crazy is that l'll come see one of the methadone patients at the hospital and when I look at the H\&P, it'll say "One pack a day of cigarettes, three glasses of wine occasionally." By definition, they're on methadone; they have a significant addiction history with opioids and there's nothing documented. I see a great tobacco and alcohol history but that really isn't a surrogate for an addiction history. I think we have to be much more thoughtful about the history.

Dr. Zavodnick: I think Dr. Kay made a really good point about naming the problem, and that's a big change that I've seen since I was a resident here not terribly long ago. I thought that when I was a resident our notes would sometimes inaccurately document the problem, like "IVDA" or IV Drug Abuse which would be listed in the social history but nowhere else. We'd have Night Float getting calls in the middle of the night and who would tell us, "They're always asking for this or that," but no one was actually naming a diagnosis for them. What I'm seeing more and more is that when we're documenting or talking to the patient or talking to the team, "Opioid Use Disorder" or "Opioid Addiction" is actually a part of the problem list and is something we create a plan to address. Our conversations with patients include what we can do about symptom management and what we can expect about pain needs during the admission. What we need to get better as providers in the Opioid Crisis is to start treating opioid use disorder as a diagnosis and as a problem instead of as some background issue that's really only going to be handled by the intern taking pages overnight.

Colin: We've already touched on this a little bit, but what differences have you noticed in patient attitudes towards opioids since the opioid epidemic was declared a national priority?

Dr. Worster: We jokingly say that I'm either begging someone to take a milligram of morphine or I'm begging them to stop taking 7,000 milligrams of morphine. That's certainly an exaggeration, but I think patient attitudes have diverged very broadly because of this crisis. Some of them have this awareness and are scared-and I think we should all have some healthy fear of opioids-but there are other patients who say, "I don't care what you tell me, this is the only thing that works for me and I'm going to take it and be damned if you're going to take it away from me." Patients are nervous about it because it's in the news and everyone's talking about it, and all of a sudden, even the process of getting pain medications is changing. You can't go to the ED and walk away with 30 days of a prescription anymore. I find that it is a more emotionallycharged patient that I see when I'm talking about opioids, one way or the other. It's becoming more of a difficult conversation and I think it's becoming really important that we all participate in with these patients. It should be something that is noted on the problem list and something we talk about with them directly-not as shaming, not something that gets marginalized, but something that is a part of how we best take care of them.

Colin: How does your management differ for patients with acute care needs as compared to patients admitted on chronic opioid therapy?

Dr. Zavodnick: I have a very low threshold for calling the Acute Pain Service. I do remember being taught in medical school about how likely we are to underdose patients with opioid dependence and that's something I worry a lot about with increased awareness; as we swing the pendulum potentially too far in the other direction and find ourselves policing people with chronic pain, deciding whether their pain is legitimate-"Well, let's not given them IV," "Let's make sure that they have an outpatient prescriber so I'm not the one prescribing it." I can see a lot of fear from providers as well. I have a low threshold to ask for help in treating acute on chronic pain because I don't know how well I'm going to be able to treat pain with the medications I have without causing respiratory depression and so I think about ketamine early. These patients need more aggressive treatment, not less.

Dr. Nash: It's almost easier inpatient, because your patient is monitored. You don't want something bad to happen to your patient, but when he or she is on a monitored unit, it's easier to make adjustments to treat acute on 
chronic pain. My thinking about some of these patients has changed; I've come to realize that patients on long-acting opioids need that medication almost to feel normal and function as their normal selves.

Dr. Zavodnick: I've also seen the lines between acute and chronic pain blur; when I see a diagnosis of "Acute on Chronic Pain," I'm not sure when we have acute pain and when we have inadequately managed chronic pain. I think it's great that we've become more aware of the risks of narcotics but there are also people who want, expect, and maybe need these medications who aren't able to access them. In the same way I sometimes have difficulty transitioning heroin users to the outpatient world, I sometimes have difficulty transitioning chronic pain patients to the outpatient world because they're started on narcotics for chronic pain in the hospital and I'm not able to find anyone willing to follow them.

Dr. Kay: I just want to make a few quick comments: The first is to remember that the goal for patients on methadone maintenance is to get them on a blocking dose such that if they used any opioids, they would not get high off of them but would still get pain management. They can get opioids, the important thing is to make sure they don't feel as though it is "stirring up" their addiction, to ask the question. The other thing is that when managing patients' acute or chronic pain, I like to think of it as a pie and explain to them, "I can't give you one pie, but I can give you eight different slices of different pies to make up a whole pie." It's not going to be that one medicine takes care of everything, pain management involves a multimodal approach. I also want them on standing NSAIDs because that will greatly reduce their opioid needs.

Dr. Worster: I think that's a great point and emphasizes the need for education about what pain is. The pathophysiology of pain is very different depending on whether you're talking about inflammatory pain or neuropathic pain or visceral pain. I didn't get that education and I think that's crucial. If you're trying to treat neuropathic pain with opioids and the patient's requiring more and more, no kidding-neuropathic pain isn't really responsive to opioids based on the pathophysiology. There's a reason why, with inflammatory pain, you get more bang for your buck using NSAIDs as opposed to opioids.

Dr. Kay: One more take-away is to ask, "What's the patient's goal with the medication?" One of my NARP patients was going for a root canal and I suggested he take 600 milligrams of ibuprofen before the lidocaine wore off. He told me, "I don't mind the pain, I want to not care about the pain." The opioid would have done that while the NSAID would not have had that effect. Sometimes patients take opioids to knock them out, help them sleep. It's always worth asking what the patient's goal is with the medication.
Brianna: Kate and Meghan, would you be willing to talk with us about the community resources available to get our patients plugged in?

Ms. Morley: Sure, I have information up here about our team and we're working to get ourselves listed as an official Consult in Epic. As far as Jefferson goes, we do have two methadone clinics, the Family Center for pregnant and parenting woman as well as NARP for everyone else. My team doesn't just refer to Jefferson resources. When patients are admitted to either Jefferson Main Campus or Methodist, I come in and really lead with motivational interviewing. Something that I have the luxury of is time and I know that not everybody has that. Social work sure doesn't, you don't as providers. I understand that. I can spend 20-30 minutes just having a conversation with patients about their use and life and traumas before I even say the word "treatment," and I think that having the time to build that relationship is really important to getting people to that motivational place where they are open to discussion.

Once patients have decided that they are ready for treatment, we work in tandem with Social Work to refer them to appropriate programs-be it methadone, suboxone, vivitrol (medication-assisted therapies), or even if they want to go into counseling, we can facilitate those warm hand-offs and make sure that there's no gap in care. The day that they're being discharged from the hospital or the following day, they're being admitted to whatever program we have decided to send them to. We can also link them to outpatient providers that aren't in the "clinic world" or the "substance abuse world" as a lot of patients who are professional aren't going to be able to engage in those programs because there are often group or individual therapy sessions that run during the day that a working individual isn't going to be able to attend. We're able to have conversations with people about what their life looks like and what program makes the most sense for them. One of the biggest barriers for us is when a patient doesn't have a urine drug screen (UDS). A patient can't be admitted to any type of medication-assisted program without a urine drug screen that's positive for an opioid. That's something we've been preaching and pushing because the lack of a UDS stops people from being admitted to the program they chose that next day. Basically without telling them to, we know and they know they're going to have to go out and use before being admitted to these programs. There are other barriers to these programs like identification and it's something to keep in mind when prescribing medication-assisted therapies as an inpatient-you need to think about the other documents that are necessary to continue these therapies as an outpatient. These are the sorts of issues that my team deals with and we want to be known! Someone once told me that we're the best-kept secret 
and Jefferson and we really don't want to be. We're trying to get our name out there as a resource for you.

Dr. Kay: You make a very good point about there being three types of opioids-natural, semi-synthetic, and synthetic. Each has a different urine drug screen, you have to specifically test for methadone and buprenorphine. If I use heroin today and you just test me for methadone, I'm going to come up negative and vise-versa.

Ms. Siddiqi: To reinforce what Meghan said, we absolutely need the UDS. Without it, I can refer until the cows come home and nothing will happen. The other barrier, as she mentioned, is the lack of ID. Some clinics are becoming more receptive to expired ID or are getting copies from previous treatment centers, but not everywhere. Today I actually called my colleagues at an agency named BHSI which helps the uninsured get insurance and, in the interim, guarantee payment to a clinic so we can get someone directly in from discharge here who is uninsured. They have remained very strict about identification, so if there's no photo ID, our ability to refer to them at the moment is limited. I've had some arguments with physicians who prescribe methadone as an inpatient to keep people in the hospital to receive the rest of their medical care. On the other hand, starting someone that we cannot comfortably get into ongoing care after discharge raises some other ethical issues as well, because no one will prescribe methadone to someone who is out in the community but not connected. Another dilemma that we have as an inpatient related to patients who are on methadone and need IV antibiotics or wound care for an extended period of time. We are kind of up the creek as there are only two facilities in area that accept these patients as inpatients; one is Kensington Hospital, the other is Valley Forge. Kensington is in a position now where they can cherry-pick and only accepts patients on Medicaid-HMO (not state Medicaid). Valley Forge is difficult to get into. If you have a patient on state Medicare, we're kind of screwed also. Medicare seems to have a bizarre notion that older people no longer have substance abuse issues and that's something that really needs to be addressed as a society. It's really criminal, in some respects, that there is no ongoing access for these patients.

Dr. Kay: Even if you're not entirely sure the patient will be followed up as an outpatient, l'd still put someone who addicted to opioids and is agreeable on methadone because if you don't, you run into two problems. First, if someone just had a heart attack, having them in withdrawal is really not safe cardiac-wise, with their pulse racing and blood pressure up. The other issue is that they're at high risk of leaving against medical advice. To get them the proper care and for medical safety, my feeling is you should be putting them on methadone.

\section{QUESTIONS}

Dr. Emily Stewart: What's the highest we can safely do that and then discharge them if they don't intend to quit?

Dr. Kay: There is no magic number. When I first started here, I was obsessed with the practice that everyone who was started on methadone in the hospital had to be tapered off before discharge. Since then I've discovered that the taper doesn't really matter and the way that I think about it now reflects something I've picked up from a colleague of mine-which is to say that they were using before they came in, unfortunately as much as l'd like to get everyone into treatment, not everyone is ready and the reality is that some people are going to leave the hospital and use again. Another thing to remember is that often patients' friends will bring them things into the hospital. So there is no magic number, but there are, of course, safety issues with higher and higher doses of methadone. We could have a whole separate Grand Rounds about inpatient management of methadone.

Dr. Zavodnick: This is about to get much, much easier. The treatment subcommittee has been working on a guideline for inpatient management of patients in withdrawal. There are a couple different pathways, including one for patients interested in seeking medicationassistant therapy in the long-term and for whom you'll need to consider outpatient care up front. The Center of Excellence is really great at this, thank you for bringing to the forefront these new resources for our patients and making the bridges to outpatient care stronger and stronger. We've included in the guidelines some tips for the providers overnight, because Psychiatry and Social Work is all well and good in the morning but we want to interns on Night Float to have support in caring for patients' withdrawal symptoms overnight and at least begin to have a conversation with the patient about whether he or she would be open to methadone or suboxone long-term which could then be started as an inpatient. We'll have guidelines about how to start these medications, how to titrate them, when to call Psychiatry. Not every patient who comes in is going to be interested in engaging in treatment and we're still going to have guidelines for robust symptom management with clonidine and Zofran, for example. Just because some patients might not be interested in methadone doesn't mean we don't want to treat their withdrawal. I think we as front-line generalist providers are going to get a little more support in making these decisions for our patients and saying, "Here are the things we offer for withdrawal management, which of these do you want to try?" and "I'm here to partner with you on this inpatient stay and we're going to call the Center for Excellence to figure out an outpatient plan, too." I think guided inpatient management of withdrawal and warm hand-offs to outpatient resources make up the gold standard that we should all be reaching for with our patients. 
Dr. Sarah Rosenberg: As a healthcare system, I can't help but feel like we're completely blowing this in a way that's baffling to me. It seems as though politicians and the laypeople are blaming doctors for the Opioid Crisis but do you have any tips on how to repair our therapeutic relationships with patients?

Dr. Worster: What goes hand-in-hand with that are conversations with patients that are like, "I want it"/"No, you can't have it"-this bargaining. I tell people all the time, "I'm fine with you being angry at me. That's okay, I can take that. I need you to hear that all I care about at the end of the day is providing you with care that is safe." Because that's the first thing we all signed up for here, to do no harm. I think with empathy, you can communicate that with a patient. We can say that it's fine for patients to feel angry, sad, or frustrated. We hold those emotions for them. But we need to have realistic one-on-one conversations with patients about safety, I think that's where repairing those therapeutic relationships start. I think most patients will partner with you if you provide a safe, non-judgmental space. I think it's a small minority that will see you as the cause of the problem or stay angry with you because you're not giving them anything at all.

Dr. Rebecca Jaffe: I'd like to commend that approach because I think what l've seen over the last five years is a discomfort about what's happening and an unwillingness to engage in that partnership. You'll see people saying, "Well, I can't prescribe that for you," or "My clinic won't prescribe opioids," and that's very different from a harm-reduction strategy where you might say, "This is the current state of where we are, this is where we plan to go long-term, what are the steps to get there?" Talk about the different things that we can do with patients to improve safety and build partnership.
Dr. Kay: I have a ton of experience with this on the benzo front and have often approached patients with terrible anxiety by saying, "I don't think this plan that we've had is working for your anxiety. The Xanax isn't cutting it, we need to do better. Let's come up with another plan."

Dr. Suchit Bhutani: I know the emergency room (ER) is a place of first-exposure for many patients. There are some centers in New Jersey which have advertised "Opioid-Free ERs," is that something that we've considered or could be changing here?

Dr. Worster: If you look at this on a larger level, the number of total ER opioid prescriptions over the last few years have gone down. Now, it defaults to a 72-hour prescription instead of seven or 10 days. I don't see how you can provide great, individualized care to people by making blanket statements. That's like saying, "Listen, I just don't do antibiotics, so we will never give you antibiotics." We also can't just stop providing good medical care. Our ER providers are very engaged in this problem. If they see my name in the PDMP, they'll give me a call and I'm happy to have that conversation with someone. That's what we really need to do, to increase our communication about this problem. 